\title{
Performa Klasifikasi K-NN dan Cross-validation pada Data Pasien Pengidap Penyakit Jantung
}

\author{
Huzain Azis ${ }^{\mathrm{a}, 1,{ }^{*}, \text { Purnawansyah a,2, Farniwati Fattaha, }}{ }^{\mathrm{a} 3}$ dan Inggrianti Pratiwi Putri a,4 \\ ${ }^{a}$ Universitas Muslim Indonesia, Urip Sumoharjo km.5, Makassar 90231, Indonesia \\ ${ }^{1}$ huzain.azis@umi.ac.id; ${ }^{2}$ Purnawansyah@umi.ac.id; ${ }^{3}$ farniwati.fattah@umi.ac.id; ${ }^{4}$ pratiwiinggrianti@gmail.com \\ *corresponding author
}

\section{INFORMASI ARTIKEL ABSTRAK}

$\begin{array}{ll}\text { Dikirim } & : 27 \text { Juli } 2020 \\ \text { Diulas } & : 01 \text { Agustus } 2020 \\ \text { Direvisi } & : 15 \text { Agustus } 2020 \\ \text { Diterbitkan } & : 27 \text { Agustus } 2020\end{array}$

Kata Kunci:

K-Nearest Neighbor

Cross-validation

Analisis performa

Penyakit cardiovascular

\begin{abstract}
Secara global, penyebab kematian nomor satu setiap tahunnya adalah penyakit cardiovascular. Penyakit cardiovascular adalah penyakit yang disebabkan gangguan fungsi jantung dan pembuluh darah, seperti Penyakit Jantung Koroner, Penyakit Gagal jantung atau Payah Jantung, Hipertensi dan Stroke. Tujuan dari penelitian ini adalah mengukur performa akurasi, presisi, recall dan $f$-measure metode K-NN dan Crossvalidation pada dataset pasien pengidap cardiovascular. dataset yang digunakan sebanyak 1000 record terdiri dari 11 atribut (age, gender, height, dll.) data pasien cardiovascular dan non cardiovascular, dataset tersebut diperoleh dari UCI Machine Learning Repository yang dikelola oleh Hungarian Institute of Cardiology Budapest: Andras Janosi, M.D., University Hospital, Zurich, Switzerland. Tahapan yang dilakukan yaitu: membagi rasio simulasi dataset 20:80, 50:50 dan 80:20, penerapan crossvalidation ( $k$-fold=10) dan klasifikasi menggunakan metode $\mathrm{K}-\mathrm{NN}$ ( $\mathrm{k}=2$ hingga $\mathrm{K}=900$ ). Hasil penelitian dari simulasi rasio dataset 50:50 memperoleh nilai akurasi $82 \%$, presisi $82 \%$, recall $82 \%$ dan $f$-measure $80 \%$ pada nilai $\mathrm{K}=13$, kemudian hasil penelitian dari simulasi rasio dataset $20: 80$ memperoleh nilai akurasi $87 \%$, presisi $87 \%$, recall $97 \%$ dan $f$-measure $92 \%$ pada nilai $\mathrm{K}=3$, serta hasil penelitian dari simulasi rasio dataset 80:20 memperoleh nilai akurasi $91 \%$, presisi $92 \%$, recall $60 \%$ dan fmeasure $72 \%$ pada nilai $\mathrm{K}=5$.
\end{abstract}

\section{Keywords:}

K-Nearest Neighbor

Crossvalidation

Perform analysis

Cardiovascular

\section{ABSTRACT}

Globally, the number one cause of death each year is cardiovascular disease. Cardiovascular disease is a disease caused by impaired function of the heart and blood vessels, such as coronary heart disease, heart failure or heart failure, hypertension and stroke. The purpose of this study was to measure the performance of accuracy, precision, recall and f-measure of the K-NN and Crossvalidation methods on a dataset of cardiovascular patients. The dataset used was 1000 records consisting of 11 attributes (age, gender, height, etc.) cardiovascular and non cardiovascular patient data, the dataset was obtained from the UCI Machine Learning Repository managed by the Hungarian Institute of Cardiology Budapest: Andras Janosi, MD, University Hospital, Zurich, Switzerland. The steps taken are: dividing the simulation ratio of the dataset to 20:80, 50:50 and 80:20, applying crossvalidation ( $\mathrm{k}$-fold $=10)$ and classification using the $\mathrm{K}-\mathrm{NN}$ method $(\mathrm{k}=2$ to $\mathrm{K}=900)$. The research results from the simulation of the dataset ratio 50:50 obtained an accuracy value of $82 \%, 82 \%$ precision, $82 \%$ recall and $80 \% \mathrm{f}$-measure at a value of $\mathrm{K}=13$, then the research results from the simulation of the dataset ratio 20:80 obtained an accuracy value of $87 \%, 87 \%$ precision, $97 \%$ recall and $92 \%$ f-measure at the value of $\mathrm{K}=3$, and the results of research from the simulation of the dataset ratio 80:20 obtained an accuracy value of $91 \%, 92 \%$ precision, $60 \%$ recall and $72 \%$ f-measure at the value $\mathrm{K}=5$.

This is an open access article under the CC-BY-SA license.

\section{Pendahuluan}

Cardiovascular merupakan organ manusia yang berperan dalam sistem peredaran darah. Penyakit cardiovascular adalah sebuah kondisi jantung tidak dapat melaksanakan tugasnya dengan baik. Secara global, penyebab kematian nomor satu setiap tahunnya adalah penyakit cardiovascular. Penyakit cardiovascular adalah penyakit yang disebabkan gangguan fungsi jantung dan pembuluh darah, seperti penyakit jantung koroner, 
penyakit gagal jantung atau payah jantung, hipertensi dan stroke. Berdasarkan data dari kemenkes RI Pada tahun 2013 diperkirakan sebanyak 12,3 juta kematian disebabkan oleh penyakit cardiovascular. Lebih dari 3 juta kematian tersebut terjadi sebelum usia 60 tahun dan seharusnya dapat dicegah. Masyarakat berusia 20 hingga 40 menderita penyakit cardiovascular sebanyak 37\% sedangkan yang berusia 40 hingga 60 sebanyak $71 \%$.

Penentuan kemiripan suatu data dapat menggunakan metode pengukuran jarak, salah satunya yaitu KNearest Neighbor (K-NN). K-NN merupakan metode pengukuran yang paling sering digunakan untuk menentukan kesamaan dua vektor. Berdasarkan penelitian sebelumnya[1], data yang digunakan 110 records pasien. 100 records digunakan sebagai data latih (training data) dan 10 records digunakan sebagai data uji (testing data). Untuk menentukan apakah seorang pasien terkena penyakit jantung digunakan 9 data terdekat atau $\mathrm{K}=9$. Perhitungan kedekatan data training dengan kasus pada data testing 3 data diprediksikan masuk kedalam kelas " 1 " tetapi ternyata termasuk kedalam kelas " 2 ". Dari 100 data training dan 10 data testing dan menggunakan metode $\mathrm{K}-\mathrm{NN}$ dengan nilai $\mathrm{K}=9$ diperoleh tingkat akurasi sebesar $70 \%$.

Lanjutan penelitian tersebut[2], dengan menggunakan metode yang sama yaitu K-NN dengan jumlah data yang di tingkatkan sebesar 1000 data pasien serta melakukan simulasi nilai $\mathrm{K}=3$ hingga $\mathrm{K}=9$. Hasil yang diperoleh dari penelitiannya yaitu nilai $\mathrm{K}=6$ memiliki nilai akurasi paling baik yaitu sebesar $85 \%$, dan nilai presisinya $78 \%$, recall 93\%, dan F-measure 85\%. Diakhir penelitiannya Hasran menyebutkan bahwa nilai akurasi $85 \%$ belum cukup baik maka di perlukan beberapa tindakan diantaranya menerapkan crossvalidation [3]-[5] untuk simulasi data pada saat pengujian. Penelitian ini berupaya melanjutkan penelitian sebelumnya yaitu dengan menganalisis performa metode K-NN serta menerapkan Crossvalidation pada data pasien Cardiovascular, harapan pada penelitian ini yaitu diperolehnya nilai performa yang baru dan dapat menjadi pembanding dengan penelitian-penelitian sebelumnya.

\section{Metode}

\section{A. Datamining}

Datamining didefinisikan sebagai proses penemuan pola dalam data. Berdasarkan tugasnya, data mining dikelompokkan menjadi deskripsi, estimasi, prediksi, klasifikasi, clustering dan asosiasi. Proses dalam tahap data mining terdiri dari tiga langkah utama, yaitu : a. Data Preparation pada langkah ini, data dipilih, dibersihkan, dan dilakukan preprocessed mengikuti pedoman dan knowledge dari ahli domain yang menangkap dan mengintegrasikan data internal dan eksternal ke dalam tinjauan organisasi secara menyeluruh. b. Algoritma data mining penggunaan algoritma data mining dilakukan pada langkah ini untuk menggali data yang terintegrasi untuk memudahkan identifikasi informasi bernilai[5]-[9].

\section{B. K-Nearest Neighbor}

K-Nearest Neighbor (K-NN) termasuk kelompok instance-based learning. Algoritma ini juga merupakan salah satu teknik lazy learning. K-NN dilakukan dengan mencari kelompok k objek dalam data training yang paling dekat (mirip) dengan objek pada data baru atau data testing. Contoh kasus, misal diinginkan untuk mencari solusi terhadap masalah seorang pasien baru dengan menggunakan solusi dari pasien lama. Untuk mencari solusi dari pasien baru tersebut digunakan kedekatan dengan kasus pasien lama, solusi dari kasus lama yang memiliki kedekatan dengan kasus baru digunakan sebagai solusinya.

Terdapat pasien baru dan 4 pasien lama, yaitu P, Q, R, dan S. Ketika ada pasien baru maka yang diambil solusi adalah solusi dari kasus pasien lama yang memikili kedekatan terbesar. Misal D1 adalah jarak antara pasien baru dengan pasien P, D2 adalah jarak antara pasien baru dengan pasien Q, D3 adalah jarak antara pasien baru dengan pasien R, D4 adalah jarak antara pasien baru dengan pasien S. Dari ilustrasi gambar terlihat bahwa D2 yang paling terdekat dengan kasus baru. Dengan demikian maka solusi dari kasus pasien Q yang akan digunakan sebagai solusi dari pasien baru tersebut.

Ada banyak cara untuk mengukur jarak kedekatan antara data baru dengan data lama (data training), diantaranya euclidean distance dan manhattan distance (city block distance), yang paling sering digunakan adalah euclidean distance. Persamaan euclidean ditunjukkan pada persamaan 1 [2], [10], [11].

$$
\text { euc }=\sqrt{ }\left(\left(a_{-} 1-b_{-} 1\right)^{\wedge} 2+\left(a_{-} 2-b_{-} 2\right)^{\wedge} 2+\cdots+\left(a_{-} n-b \_n\right)^{\wedge} 2\right)
$$

Alur kerja K-NN diilustrasikan pada Gambar 1.

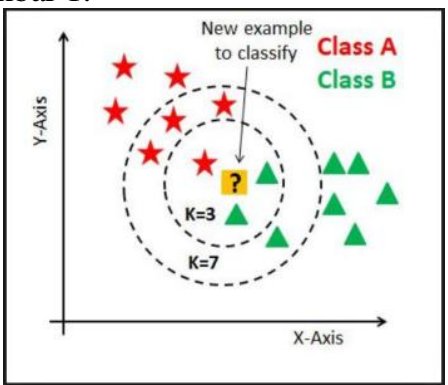

Gambar 1. Contoh Alur Kerja K-NN 


\section{Crossvalidation}

Crossvalidation atau dapat disebut estimasi rotasi adalah sebuah teknik validasi model untuk menilai bagaimana hasil statistik analisis akan menggeneralisasi kumpulan data independen[12][13]. Teknik ini utamanya digunakan untuk melakukan prediksi model dan memperkirakan seberapa akurat sebuah model prediktif ketika dijalankan dalam praktiknya. Salah satu teknik dari validasi silang adalah $k$-fold crossvalidation, yang mana memecah data menjadi K bagian set data dengan ukuran yang sama. Penggunaan $k$-fold $=5$ cross-validation untuk menghilangkan bias pada data. Pelatihan dan pengujian dilakukan sebanyak K. Alur kerja cross-validation diilustrasikan pada Gambar 2.

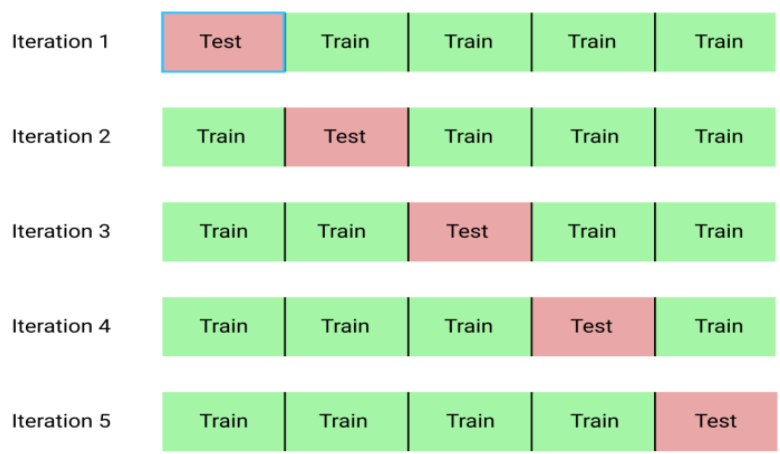

Gambar 2. Contoh simulasi crossvalidation.

\section{Analsis Performa}

Tahap terakhir setelah penerapan metode klasifikasi adalah menghitung performa, adapun persamaan performa menggunakan confusion matrix yang mana untuk membantu menghitung nilai akurasi, presisi, recall dan $f$-measure [14]-[16]. Persamaan yang digunakan untuk menghitung akurasi ditunjukkan pada persamaan 2, penerapan perhitungan akurasi yang digunakan pada penelitian ini adalah balanced-accuracy (ba) dimana berfungsi untuk menangani multiclass klasifikasi dengan data yang tidak seimbang [17], [18].

$$
\begin{aligned}
& \text { accuracy }=\frac{T P+T N}{T P+T N+F P+F N} \\
& \text { b. } a=1 / 2\left(\frac{T P}{T P+F N}+\frac{T N}{T N+F P}\right)
\end{aligned}
$$

Proses klasifikasi multiclass, perhitungan performa presisi, recall, dan $f$-measure dapat diterapkan pada setiap label secara independen[19], [20]. presisi menggunakan persamaan 3, persamaan 4 menunjukan perhitungan performa recall dan persamaan 5 untuk $f$-measure [21], [22].

$$
\begin{gathered}
\text { precision }=\frac{T P}{T P+F P} \\
\text { recall }=\frac{T P}{T P+F N} \\
f-\text { measure }=\frac{\text { precision } * \text { recall }}{\text { precison }+ \text { recall }}
\end{gathered}
$$

\section{Hasil dan Pembahasan}

Implementasi metode K-NN pada tahap ini merupakan contoh perhitungan manual mulai dari penetapan data latih dan data uji, implementasi metode K-NN hingga perhitungan performa. Berikut ini 12 sample data yang akan di terapkan untuk perhitungan manual di tunjukkan pada Tabel 1 menunjukan 12 sampel data.

Tabel 1 DataSet Sample

\begin{tabular}{ccccccccccccc}
\hline age & gender & Height & weight & ap_hi & ap_lo & chol & gluc & smoke & alco & acti ve & cardio \\
\hline 16003 & 1 & 162 & 74.0 & 140 & 100 & 2 & 1 & 0 & 0 & 1 \\
\hline 16039 & 2 & 180 & 90.0 & 140 & 90 & 2 & 2 & 0 & 0 & 0 \\
\hline 19029 & 1 & 115 & 64.0 & 120 & 70 & 1 & 1 & 0 & 0 & 1 \\
\hline 22821 & 2 & 168 & 80.0 & 160 & 100 & 1 & 1 & 0 & 0 & 1 \\
\hline 20395 & 1 & 164 & 70.0 & 120 & 70 & 1 & 1 & 0 & 0 & 0 \\
\hline
\end{tabular}




\begin{tabular}{cccccccccccc}
\hline age & gender & Height & weight & ap_hi & ap_lo & chol & gluc & smoke & alco & acti ve & cardio \\
\hline 21473 & 2 & 174 & 90.0 & 140 & 80 & 1 & 1 & 1 & 1 & 0 & 1 \\
\hline 21758 & 1 & 165 & 65.0 & 140 & 90 & 1 & 1 & 0 & 0 & 1 & 1 \\
\hline 21166 & 2 & 162 & 59.0 & 140 & 90 & 2 & 1 & 1 & 0 & 1 & 1 \\
\hline 23444 & 1 & 175 & 76.0 & 120 & 80 & 1 & 1 & 0 & 1 & 1 & 1 \\
\hline 18958 & 1 & 149 & 62.0 & 180 & 110 & 2 & 1 & 0 & 0 & 1 & 1 \\
\hline
\end{tabular}

Hal yang dilakukan setelah mempersiapkan data adalah melakukan pembagian data latih dan data uji sesuai perencanaan yaitu menggunakan konsep cross-validation. Adapun jumlah $k$-fold yang digunakan adalah $k$-fold=10. Gambar 3 menunjukkan implementasi croos-validation pada penelitian ini

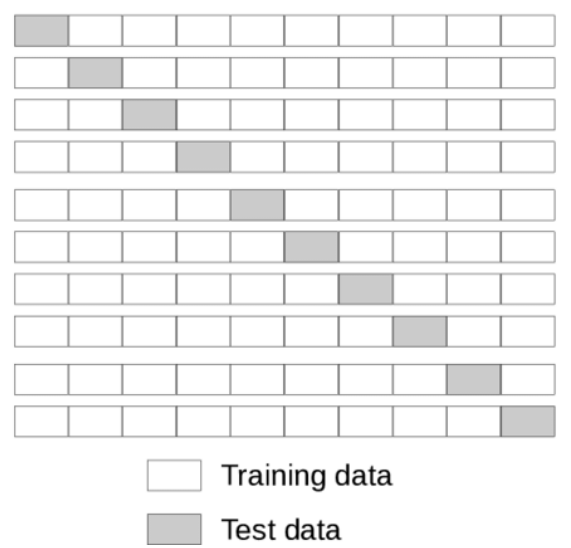

Gambar 3. Implementasi cross-validation $k$-fold $=10$
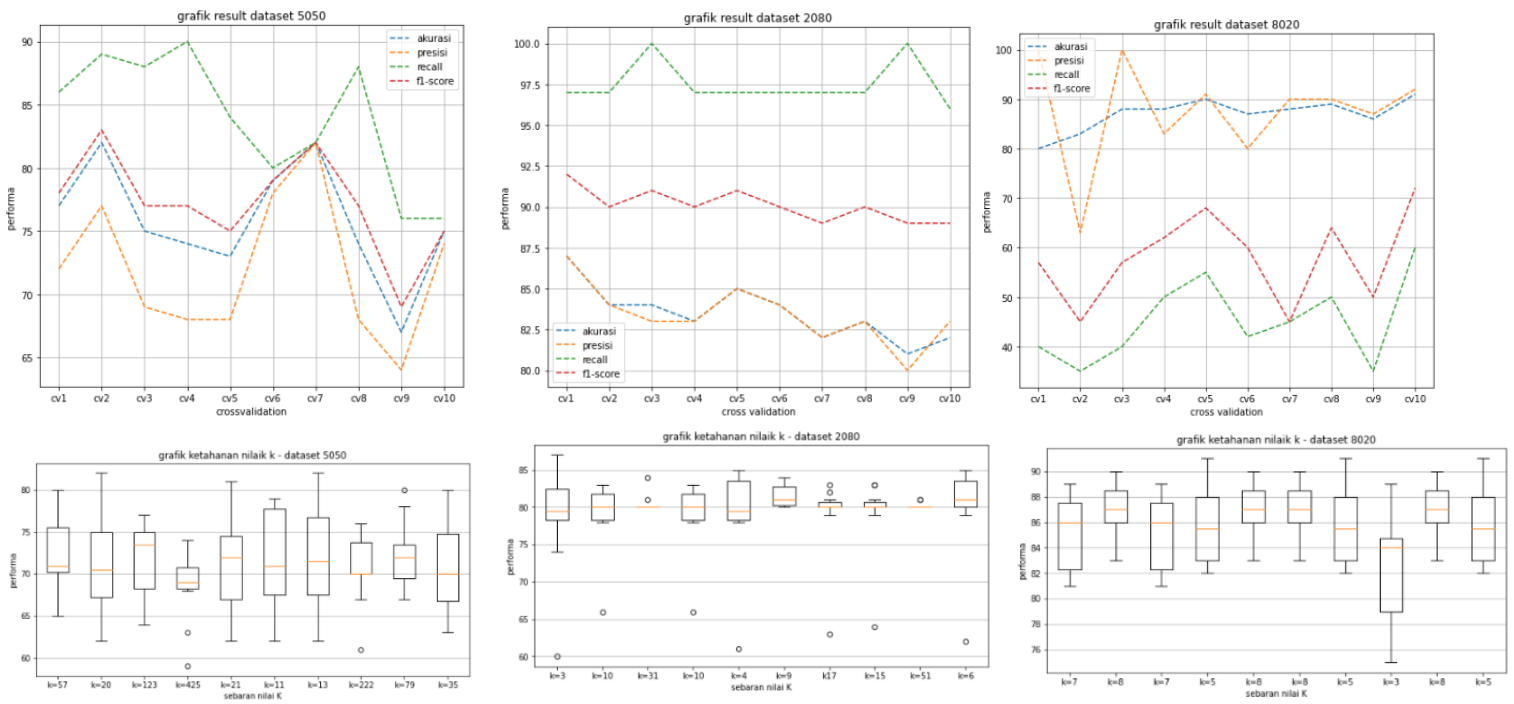

Gambar 4. Hasil implementasi metode KNN dan cross-validation

Setelah proses pembagian data telah dilakukan, maka tahap selanjutnya adalah penerapan metode KNN, implementasi metode K-NN pada penelitian ini menggunakan library machine learning sklearn, penerapannya dilakukan pada pembagian data cross-validation yang telah dilakukan sebelumnya dan pada rasio data 20:80, 80:20 serta 50:50. Nilai ketetanggapan yang diuji coba adalah nilai $\mathrm{K}=2$ hingga $\mathrm{k}=\mathrm{jumlah}$ data uji atau sebesar $\mathrm{k}=900$.

Gambar 4 menunjukkan tahap akhir dari penelitian ini yaitu merepresentasikan hasil pengujian performa yaitu akurasi, presisi, recall dan $f$-measure, keseluruhan output dari penelitian ini, dibagi menjadi dua bagian yaitu line graph dan boxplot. Pada line graph terbagi menjadi tiga bagian yang mana mewakili setiap rasio yaitu rasio 20:80, 80:20 dan 50:50. Setiap line graph merepresentasikan nilai akurasi, presisi dan recall untuk $10 \mathrm{k}$-fold crossvalidation. Sedangkan representasi boxplot pada Gambar 4 terbagi menjadi tiga bagian yang mewakili setiap rasio dimana nilai yang dibentuk menjadi boxplot tersebut adalah 10 nilai akurasi tertinggi pada setiap crossvalidation. Adanya boxplot maka dapat terlihat nilai-nilai performa yang menjadi nilai outlier atau nilai yang tidak dapat dijadikan acuan sebagai model. 
Berdasarkan Gambar 4 dapat dilihat bahwa terdapat tiga nilai performa terbaik pada setiap rasionya yaitu $82 \%, 87 \%$ dan $91 \%$ untuk akurasinya, namun performa terbaik dengan mempertimbangkan nilai akurasi, presisi, recall,f-measure serta representasi boxplot jatuh pada rasio 80:20 dengan nilai akurasi 91\%, dikarenakan nilai tersebut memiliki keseimbangan antara presisi dan recall yang paling baik serta pada rasio tersebut nilai outlier pada boxplot tidak ditemukan. Tabel 2 merepresentasikan keseluruhan hasil pengujian disertai dengan perbandingan hasil pengujian penelitian ini dengan penelitian sebelumnya.

Tabel 2. Perbandingan hasil penelitian

\begin{tabular}{|c|c|c|c|c|c|c|c|c|c|}
\hline No & Peneliti & Metode & $\begin{array}{l}\text { Jumlah } \\
\text { / Rasio } \\
\text { dataset }\end{array}$ & $\begin{array}{c}\text { Jumlah } \\
\text { Data } \\
\text { Training } \\
\end{array}$ & $\begin{array}{c}\text { Jumlah } \\
\text { Data } \\
\text { Testing } \\
\end{array}$ & Akurasi & Presisi & Recall & f-measure \\
\hline 1. & $\begin{array}{c}\text { Mei } \\
(2014) \\
{[1]}\end{array}$ & $\mathrm{K}-\mathrm{NN} \mathrm{K}=6$ & 110 & 100 & 10 & $85 \%$ & $78 \%$ & $93 \%$ & $85 \%$ \\
\hline 2. & $\begin{array}{c}\text { Hasran } \\
(2019) \\
{[2]}\end{array}$ & K-NN K=6 & $1000 / 50: 50$ & 900 & 100 & $85 \%$ & $79 \%$ & $93 \%$ & $85 \%$ \\
\hline \multirow{3}{*}{3.} & \multirow{3}{*}{$\begin{array}{l}\text { Huzain } \\
(2020)\end{array}$} & $\mathrm{K}-\mathrm{NN} \quad \mathrm{K}=13$ & $1000 / 50: 50$ & 900 & 100 & $82 \%$ & $82 \%$ & $82 \%$ & $82 \%$ \\
\hline & & $\mathrm{K}-\mathrm{NN} \mathrm{K}=3$ & $1000 / 20: 80$ & 900 & 100 & $87 \%$ & $87 \%$ & $97 \%$ & $92 \%$ \\
\hline & & $\mathrm{K}-\mathrm{NN} \mathrm{K}=5$ & $1000 / 80: 20$ & 900 & 100 & $91 \%$ & $92 \%$ & $60 \%$ & $72 \%$ \\
\hline
\end{tabular}

\section{Kesimpulan}

Berdasarkan hasil penelitian ini maka penulis dapat menarik kesimpulan yaitu dataset1 (dataset 50:50) di peroleh nilai performa paling baik pada nilai akurasi sebesar $82 \%$, presisi $82 \%$, recall $82 \%$ dan $f$-measure $82 \%$, pada $\mathrm{K}=13$. Dataset2 (dataset 20:80) di peroleh nilai performa paling baik pada nilai akurasi sebesar $87 \%$, presisi $87 \%$, recall $97 \%$, dan $f$-measure $92 \%$, pada $\mathrm{K}=3$. Dataset3 (dataset $80: 20$ ) di peroleh nilai performa paling baik pada nilai akurasi sebesar $91 \%$, presisi $92 \%$, recall $60 \%$ dan $f$-measure $72 \%$, pada $\mathrm{K}=5$. Performa terdapat pada rasio 80:20 dengan akurasi 91\% dengan pertimbangan bahwa baiknya keseimbangan nilai presisi dan recall serta tidak adanya nilai outlier pada boxplot. Berdasarkan seluruh nilai yang telah didapatkan serta hasil perbandingan dengan penelitian sebelumnya, nilai performa yang diperoleh pada penelitian ini lebih baik di banding dengan nilai performa penelitian sebelumnya, serta menunjukkan bahwa nilai performa yang diperoleh dapat lebih baik karena dilakukan berbagai simulasi rasio data, penerapan cross-validation serta pengujian keseluruh nilai $\mathrm{K}$ pada K-NN

[1] M. Lestari, "Penerapan Algoritma Klasifikasi Nearest Neighbor (K-NN) Untuk Mendeteksi Penyakit Jantung," Fakt. Exacta, vol. 7, no. September 2010, pp. 366-371, 2014.

[2] Hasran, "Klasifikasi Penyakit Jantung Menggunakan Metode K-Nearest Neighbor," Indones. J. Data Sci., vol. 1, no. 1, pp. 1-4, 2020.

[3] F. T. Admojo and Ahsanawati, "Klasifikasi Aroma Alkohol Menggunakan Metode KNN," Indones. J. Data Sci., vol. 1, no. 2, pp. 34-38, 2020.

[4] A. Maulida, "Penerapan Metode Klasifikasi K-Nearest Neigbor pada Dataset Penderita Penyakit Diabetes," Indones. J. Data Sci., vol. 1, no. 2, pp. 29-33, 2020.

[5] D. Cahyanti, A. Rahmayani, and S. Ainy, "Analisis performa metode Knn pada Dataset pasien pengidap Kanker Payudara,” Indones. J. Data Sci., vol. 1, no. 2, pp. 39-43, 2020.

[6] Y. Lukito and A. R. Chrismanto, "Perbandingan Metode-Metode Klasifikasi untuk Indoor Positioning System," J. Tek. Inform. dan Sist. Inf., vol. 1, no. 2, pp. 123-131, 2015, doi: 10.28932/jutisi.v1i2.373.

[7] N. Fadhillah, H. Azis, and D. Lantara, "Validasi Pencarian Kata Kunci Menggunakan Algoritma Levenshtein Distance Berdasarkan Metode Approximate String Matching," Pros. Semin. Nas. Ilmu Komput. dan Teknol. Inf., vol. 3, no. 2, pp. 3-7, 2018.

[8] A. A. Karim, H. Azis, and Y. Salim, "Kinerja Metode C4.5 dalam Penyaluran Bantuan Dana Bencana 1,” Pros. Semin. Nas. Ilmu Komput. dan Teknol. Inf., vol. 3, no. 2, pp. 84-87, 2018.

[9] A. Fitria and H. Azis, "Analisis Kinerja Sistem Klasifikasi Skripsi menggunakan Metode Naïve Bayes Classifier,” Pros. Semin. Nas. Ilmu Komput. dan Teknol. Inf., vol. 3, no. 2, pp. 102-106, 2018.

[10] M. M. Baharuddin, T. Hasanuddin, and H. Azis, “Analisis Performa Metode K-Nearest Neighbor untuk Identifikasi Jenis Kaca,” Ilk. J. Ilm., vol. 11, no. 28, pp. 269-274, 2019.

[11] H. Azis, F. T. Admojo, and E. Susanti, "Analisis Perbandingan Performa Metode Klasifikasi pada Dataset Multiclass Citra Busur Panah," Techno.Com, vol. 19, no. 3, 2020.

[12] M. J. Hartmann and G. Carleo, "Neural-Network Approach to Dissipative Quantum Many-Body Dynamics," Phys. Rev. Lett., vol. 122, no. 25, p. 250502, Jun. 2019, doi: 10.1103/PhysRevLett.122.250502.

[13] K. Crammer, "On the algorithmic implementation of multiclass kernel-based vector machines," $J$. Mach. Learn. Res. - JMLR, vol. 2, no. 2, pp. 265-292, 2002. 
[14] A. Tharwat, "Linear vs. quadratic discriminant analysis classifier: a tutorial," Int. J. Appl. Pattern Recognit., vol. 3, no. 2, p. 145, 2016, doi: 10.1504/ijapr.2016.079050.

[15] P. A. Flach and M. Kull, "Precision-Recall-Gain curves: PR analysis done right," Adv. Neural Inf. Process. Syst., vol. 2015-Janua, pp. 838-846, 2015.

[16] L. Nurhayati and H. Azis, "Perancangan Sistem Pendukung Keputusan Untuk Proses Kenaikan Jabatan Struktural Pada Biro Kepegawaian," Semin. Nas. Teknol. Inf. dan Multimed., pp. 6-7, 2016.

[17] A. Tharwat, "Classification assessment methods," Appl. Comput. Informatics, 2018, doi: 10.1016/j.aci.2018.08.003.

[18] K. H. Brodersen, C. S. Ong, K. E. Stephan, and J. M. Buhmann, "The balanced accuracy and its posterior distribution," Proc. - Int. Conf. Pattern Recognit., pp. 3121-3124, 2010, doi: 10.1109/ICPR.2010.764.

[19] T. Hastie, S. Rosset, J. Zhu, and H. Zou, "Multi-class AdaBoost,” Stat. Interface, vol. 2, no. 3, pp. 349360, 2009, doi: 10.4310/sii.2009.v2.n3.a8.

[20] R. Puri and K. Khamrui, "Application of Quantitative Descriptive Analysis (QDA), Principal Component Analysis (PCA) and Response Surface Methodology (RSM) in standardization of chamcham making.," 2015.

[21] S. Paembonan et al., "Combination of K-Means and Profile Matching for Drag Substitution," in 2018 2nd East Indonesia Conference on Computer and Information Technology (EIConCIT), Nov. 2018, pp. 180-183, doi: 10.1109/EIConCIT.2018.8878539.

[22] D. Chicco and G. Jurman, "The advantages of the Matthews correlation coefficient (MCC) over F1 score and accuracy in binary classification evaluation," BMC Genomics, vol. 21, no. 1, pp. 1-13, 2020, doi: 10.1186/s12864-019-6413-7. 